A C G

Rec. Nat. Prod. 12:4 (2018) 323-331

records of natural

publications

products

\title{
Fatty Acid, Tocopherol, Sterol Compositions and Antioxidant Activity of Three Garcinia Seed Oils
}

\section{Doan Lan Phương $\odot^{* 1,2}$, Nguyen Thi Thuy $\odot^{2,3}$, Pham Quoc Long ${ }^{1,2}$, Pham Minh Quan ${ }^{4}$, Tran Thi Thu Thuy $\odot^{1,2}$, Pham Thi Hong Minh $\odot^{1,2}$, Ping-Chung Kuo $\odot^{5}$ andTran Dinh Thang $\odot^{* 6}$}

\author{
${ }^{1}$ Institute of Natural Products Chemistry, Vietnam Academy of Science and Technology, \\ 18 Hoang Quoc Viet, Cau Giay, Viet Nam \\ ${ }^{2}$ Graduate University of Science and Technology Vietnam Academy of Science and Technology, \\ 18 Hoang Quoc Viet, Cau Giay, Viet Nam \\ ${ }^{3}$ Thai Nguyen University of Agriculture and Forestry Quyet Thang, Thai Nguyen City, Viet nam \\ ${ }^{4}$ University of Science and Technology of Hanoi, Vietnam Academy of Science and Technology, \\ 18 Hoang Quoc Viet, Cau Giay, Viet Nam \\ ${ }^{5}$ School of Pharmacy, College of Medicine, National Cheng Kung University,Tainan 701, Taiwan, \\ $R O C$ \\ ${ }^{6}$ School of Chemistry, Biology and Enviroment, Vinh University, Vinh City, Vietnam
}

(Received September 01, 2017; Revised November 6, 2017; Accepted November 11, 2017)

\begin{abstract}
The fatty acid, tocopherol, and sterol contents of the extracted seed oils from three Garcinia species, including G. hanburyi Hook. f., G. multiflora Champ. ex Benth., and G. gaudichaudii Planch. \& Triana, were analyzed. The results showed that the Garcinia seeds contained a high amount of oil (16.28-29.91\%). The major monounsaturated and saturated fatty acids were oleic acid (82.97\% in G. multiflora and $45.37 \%$ in G. hanburyi) and stearic acid $(58.87 \%$ in G. gaudichaudii and $50.12 \%$ in G. hanburyi). In addition, three extracted oils exhibited moderate antioxidant activity with $G$. hanburyi displayed the strongest activity with $\mathrm{IC}_{50}$ value of $6.34 \pm 0.43 \mu \mathrm{g} / \mathrm{mL}$ or $\mathrm{EC}_{50}=11.71 \pm 0.22 \mu \mathrm{g} / \mathrm{mL}$.
\end{abstract}

Keywords: Seed oil; fatty acid; tocopherol; sterol; Garcinia; antioxidant activity. (C) 2018 ACG Publications. All rights reserved.

\section{Introduction}

Garcinia is a large genus that occurs mainly in the tropical countries. The fruits of most Garcinia species are eatable for human and animals, and some are highly esteemed in some region. Seed of some species in this genus are sources of edible fat known as "kokam butter" or "kokam fat" for G. indica and "tamal" for G. morella. Species in the family are mainly wood or shrubs, characterized by yellow latex, branches, usually horizontal. Some species are trees fruits and many species contain active compounds such as xanthones, benzophenones, flavonoids, and tannins [1]. Although there are lot of works in Vietnam related to the economic values and preliminary chemical research of some other species [2-6], three Garcinia species mentioned herein have not been studied for their chemical compositions extensively. G. hanburyi was reported to show anti-inflammatory, analgesic, antibacterial, and antipyretic activities [7,8]. G. multiflora was also known for its antioxidant and antibacterial, especially anti-HIV activity $[9,10]$. Comparatively, the third species $G$.

\footnotetext{
*Corresponding author: E- Mail: thangtd@ vinhuni.edu.vn
} 
gaudichaudii was lack of bioactivity report. Plant seeds are important oil sources of nutritional and pharmaceutical industries, and therefore detailed knowledge of the chemical composition of seed oil is very important for their application [11,12]. However, the comprehensive constitution of Garcinia seed oils is still poorly investigated. The present research is the first report of fatty acid, tocopherol and sterol compositions and antioxidant activity of seed oils from three Garcinia species, $G$. hanburyi Hook f., G. multiflora Champ. ex Benth., and G. gaudichaudii Planch. \& Triana. Hopefully, it would provide systematic information regarding the further application of these species.

\section{Materials and Methods}

\subsection{Plant Materials}

Three Garcinia seeds including G. hanburyi Hook f., G. multiflora Champ. ex Benth., and G. gaudichaudii Planch. \& Triana were collected from Phu Quoc province, Vietnam in 2016. Voucher specimens VNMN-B 2015.121, VNMN-B 2015.123 and VNMN-B 2015.130 were kept at Department of Organic Biochemistry, Institute of Natural Products Chemistry, VAST and identified and set herbarium number by Dr. Nguyen Quoc Binh (Department of Biology, Vietnam National Museum of Nature, VAST), stored at $-4{ }^{\circ} \mathrm{C}$ for further experiments.

\subsection{Oil Extraction}

The oils were extracted from three Garcinia seeds by Soxhlet extraction according to method [13] with some modifications. In brief, $10 \mathrm{~g}$ sample of each seed was ground in a ball mill and extracted with $200 \mathrm{~mL}$ of petroleum ether in a Twisselmann apparatus for $6 \mathrm{hrs}$. The solvent was removed with a rotary evaporator at $40{ }^{\circ} \mathrm{C}$ and 25 torr. The oil contents obtained by Soxhlet extraction were $17.73 \%$ for G. hanburyi, $29.91 \%$ for G. multiflora, and $16.28 \%$ for G. gaudichaudii respectively. The oils was dried by a gentle stream of nitrogen and stored at $-20{ }^{\circ} \mathrm{C}$ until use.

\subsection{Analysis of Fatty Acid, Tocopherol and Sterol Compositions}

Fatty acid was determined by gas chromatography followed the ISO draft standard method [14]. In brief, $10 \mathrm{mg}$ of oil was dissolved in $1 \mathrm{~mL}$ of petroleum ether. Then, $25 \mu \mathrm{L}$ of $2 \mathrm{M}$ sodium methanolate methanol solution was added, and the closed vial was agitated vigorously for $1 \mathrm{~min}$. About $20 \mu \mathrm{L}$ water was added, and after centrifugation the aqueous phase was removed. Then $20 \mu \mathrm{L}$ methyl orange in $0.1 \mathrm{~N} \mathrm{HCl}$ was added as a $\mathrm{pH}$ indicator. The mixture was agitated carefully and different derivatives was analyzed by a Hewlett-Packard Gas Chromatography Instrument Model 5890 Series II/5989 A, equipped with a $0.25 \mathrm{~mm}$ ZB-1 fused-silica capillary column (30 m x $0.25 \mu \mathrm{m}$ i.d.; Phenomenex, Torrance, CA). The carrier gas was helium at a flow rate of $1.0 \mathrm{~mL} / \mathrm{min}$.

Tocopherol determination was accomplished by HPLC analysis [15]. A solution of $250 \mathrm{mg}$ oil in $25 \mathrm{~mL}$ heptane was used for the HPLC analysis conducted on a Merck-Hitachi low-pressure gradient system, fitted with a L-6000 pump, a Merck-Hitachi F-1000 fluorescence spectrophotometer (detector wavelengths at $295 \mathrm{~nm}$ for excitation, and at $330 \mathrm{~nm}$ for emission) and Chemstation integration software. About $20 \mu \mathrm{L}$ of the sample was injected by a Merck 655- A40 autosampler onto a Diol phase HPLC column $(250 \mathrm{~mm} \times 4.6 \mathrm{~mm}$ i.d.; Merck), which was used at a flow rate of $1.3 \mathrm{~mL} / \mathrm{min}$. The mobile phase used was heptane/tert-butyl methyl ether $(99+1, \mathrm{v} / \mathrm{v})$. The results are given as $\mathrm{mg}$ vitamin E/100g oil.

Sterol was determined according to the official IOOC (the International Olive Oil Council) method [16]. Oil sample $(15 \mathrm{~g})$ was saponified by $50 \mathrm{~mL}$ of $2 \mathrm{~N}$ ethanolic potassium hydroxide solution. The unsaponifiable fraction was dissolved in chloroform, and approximately $20 \mathrm{mg}$ were loaded on a basic silica TLC plate. The sterol and triterpenediol fraction was separated by eluent mixture with hexane and diethyl ether $65: 35(\mathrm{v} / \mathrm{v})$. The corresponding band was visualized under UV light after being sprayed with a 2,7-dichlorofluorescein in $0.2 \%$ ethanolic solution, then scraped off with a spatula, and extracted with chloroform. After the extract was evaporated to dryness, sterols and 
triterpenediols were converted into trimethylsilyl ethers by the addition of pyridine hexamethyldisilizane-trimethylchlorosilane $(9: 3: 1, \mathrm{v} / \mathrm{v} / \mathrm{v})$. The resulting mixture was kept for 15 min and then centrifuged. The analysis of sterols was performed on a fused silica capillary column coated with $2 \%$ isopropanol $/ 98 \%$ hexane $(30 \mathrm{~m}$ x $0.32 \mathrm{~mm}$ i.d., film thickness $0.25 \mu \mathrm{m}$; Rtx-5: Restek Corporation, Bellefonte, PA, USA; or HP-5: Agilent Technologies Inc., Little Falls, DE, USA) with a Hewlett Packard series 6890 GC (Waldbronn, Germany) equipped with a split/splitless injector, an autosampler, and a flame ionization detector (FID). An aliquot of $1.0 \mathrm{~mL}$ of derivatized sample solution was introduced into the column via split injection $\left(300^{\circ} \mathrm{C}\right.$, split ratio $\left.1: 50\right)$. The components were separated isothermally at $300{ }^{\circ} \mathrm{C}$ and detected with the FID (at $310{ }^{\circ} \mathrm{C}$ ). The carrier gas was helium. To identify the individual peaks of sterols, the determination of relative retention times (RRT) for sterols was carried out according to the majority compound of sterols ( $\beta$-sistosterol), knowing that RRT ( $\beta$-sitosterol) equal to 1 as described by COI [17].

\subsection{Determination of Antioxidant Activity with the DPPH Free Radical Scavenging Method}

For determination of the antioxidant activity of different extracts, three different antioxidant assay had been utilized.

\subsubsection{DPPH Free Radical Scavenging Method [18]}

An aliquot $(0.5 \mathrm{~mL})$ of the DPPH solution (about $50 \mathrm{mg} / 100 \mathrm{~mL}$ ) was diluted in $4.5 \mathrm{~mL}$ of methanol, and $0.1 \mathrm{~mL}$ of a methanol solution of the extract was added. The mixture was shaken vigorously and allowed to stand for $45 \mathrm{~min}$ in the dark. The decrease in absorbance was measured at $515 \mathrm{~nm}$ against a blank (without extract) with a spectrophotometer. From a calibration curve obtained with different amounts of extracts, the $\mathrm{IC}_{50}$ which was required to quench $50 \%$ of the initial $\mathrm{DPPH}$ radicals under the experimental conditions given was calculated.

\subsubsection{FRAP Ferric Reducing Ability of Plasma [19]}

The FRAP reagent contained 2,4,6-tripyridyl-s-triazine (TPTZ) solution $(20 \mathrm{mM})$ in $\mathrm{HCl}(40$ $\mathrm{mM}), \mathrm{FeCl}_{3} \cdot 6 \mathrm{H}_{2} \mathrm{O}(20 \mathrm{mM})$ and $0.3 \mathrm{M}$ acetate buffer with $\mathrm{pH}$ 3.6. FRAP reagent (1.8 mL) mixed with $0.2 \mathrm{~mL}$ of test sample was incubated at $37^{\circ} \mathrm{C}$ for $10 \mathrm{~min}$ in a water bath. After incubation, the absorbance was measured immediately at $593 \mathrm{~nm}$. The calibration curve was plotted with absorbance vs concentration of $\mathrm{FeSO}_{4}$ in the range of $0-1 \mathrm{mM}$ and the total antioxidant activity was expressed as $\mu \mathrm{mol} \mathrm{Fe}(\mathrm{II}) / \mathrm{g}$ extract.

\subsubsection{TEAC Trolox Equivalent Antioxidant Capacity [20]}

The green radical cation $\mathrm{ABTS}^{+}$was generated by oxidation of ABTS [2,2'-azinobis(3ethylbenzothiazoline-sulfonic-6-acid) diammonium salt] $7 \mathrm{mM}$ with $\mathrm{K}_{2} \mathrm{~S}_{2} \mathrm{O}_{8} 2.45 \mathrm{mM}$ and allowing the mixture in the dark at room temperature for $16 \mathrm{~h}$. The $\mathrm{ABTS}^{+}$solution was diluted to an absorbance of $0.7 \pm 0.02$ at $734 \mathrm{~nm}$. After addition of $1900 \mu 1$ of diluted ABTS $^{+}$solution to $100 \mu 1$ of test substances or Trolox (6-hydroxy-2,5,7,8-tetramethylchroman-2-carboxylic acid) standards, the absorbance was taken 1-6 min after initial mixing. The percentage inhibition of absorbance of ABTS ${ }^{+}$ at $734 \mathrm{~nm}$ was then calculated and plotted towards concentrations of test/standard substances as a function of time or concentration. The TEAC value was finally calculated as the ratio of the slopes of the linear regression of the concentration-response curves of the test substances towards the reference substance (Trolox).

\section{Results and Discussion}

The oil contents obtained by Soxhlet extraction were $17.73 \%$ for G. hanburyi, $29.91 \%$ for $G$. multiflora, and $16.28 \%$ for G. gaudichaudii, respectively. Comparatively, the oil contents reported for G. indica is about $50 \%$, for G. xanthochymus is $16.9 \%$, and for G. gummi-gutta is $11.21 \%$ [21,22]. The oil contents of three seeds studied herein were lower than those of seeds used in commercial oils, 
such as rapeseed and sesame oils (about $40 \%$ ); and were similar to that of soybean oil (about $20 \%$ ). Regarding the economic aspects of oilseed production, a high oil content is important for the utilization of seeds $[23,24]$. Therefore, the oils from three Garcinia species were further investigated for the chemical compositions including the fatty acids, tocopherols and sterols, to elucidate the bioactive potentials of these seeds.

The fatty acid compositions of three seed samples were summarized in Table 1 . Despite of three studied species belong to the same genus, the fatty acids composition of them are different significantly. It is determined that the seed oil of all three species contain common fatty acids in different proportions, for example: stearic acid (18:0) represent for saturated fatty acids and in unsaturated fatty acids, there are oleic acid [18:1(n-9)] and linoleic acid [18:2(n-6)].The literature reported that the higher portions of total saturated fatty acids increase the level of low density cholesterol in the blood serum, which leads to a higher risk for heart diseases and arteriosclerosis $[25,26]$. Oleic acid is the predominant monounsaturated fatty acids identified in G. multiflora (83.46 $\%$ ) which reveals that the seed oil of G. multiflora are a rich source of unsaturated fatty acids. In $G$. hanburyi seed oil, the content of oleic acid is $45.50 \%$, however, the content of this acid in $G$. gaudichaudii is only $7.82 \%$. It is reported that the contents of oleic acid in two other species G. indica and G. morella were $53 \%$ and $50 \%$, respectively [27]. Various reports have also shown higher oleic acid contents in G. gummi-gutta $(63.74 \%)$, G. indica (67.06 \%), G. xanthochymus (51.68 \%) [27], and G. mangostana (45.38\%) [28]. Oleic acid is the most common dietary monounsaturated fatty acid, found in most animal fats, including poultry, beef and lamb, as well as olives, nuts, seeds, and corn. It is reported that oleic acid is effective to lower low-density lipoprotein (LDL) cholesterol level [29,30]. Therefore, the high quantity of oleic acid in the Garcinia seed oils may be good for health. The other major fatty acid identified in G. multiflora was stearic acid (11.49\%). Comparatively, it was found to be a major fatty acid in seed oils of G. gaudichaudii (58.87\%) and G. hanburyi (50.12\%). Fats or oils abundant with stearic acid are more common in animal fats (up to $30 \%$ ) than in vegetable oils (typically $<5 \%$ ). The important exceptions are cocoa butter and shear butter, where the stearic acid contents (as a triglyceride) are 28-45\% [31]. It also indicated the potential of these Garcinia seed oils. Linoleic acid was found to be the highest concentration in G. gaudichaudii $(30.46 \%)$ meanwhile in $G$. hanburyi and G. multiflora were only 0.77 and $0.37 \%$ respectively. Similar amounts of linoleic acid were also found in the seed oils like corn, soybean, safflower, sunflower [26,32]. In contrast, linolenic acid $(\mathrm{C} 18: 3(9,12,15))$ was not found in genus Garcinia.

Table 1. Fatty acid composition (\%) of three Garcinia seed oils

\begin{tabular}{lcccc}
\hline \multicolumn{1}{c}{ Fatty acid } & KI & G. hanburyi & G. multiflora & G. gaudichaudii \\
\hline C16:0 & 1984 & $2.11 \pm 0.04$ & $4.31 \pm 0.01$ & $1.71 \pm 0.02$ \\
C18:0 & 2114 & $50.12 \pm 0.01$ & $11.49 \pm 0.01$ & $58.87 \pm 0.04$ \\
C18:1(n-9) & 2141 & $45.50 \pm 0.03$ & $83.46 \pm 0.10$ & $7.82 \pm 0.10$ \\
C18:1(n-7) & 2161 & $0.25 \pm 0.02$ & $<\mathrm{LOQ}$ & $0.21 \pm 0.03$ \\
C18:2(n-6) & 2173 & $0.77 \pm 0.01$ & $0.37 \pm 0.01$ & $30.46 \pm 0.20$ \\
C18:3(n-3) & 2162 & $0.12 \pm 0.00$ & $<\mathrm{LOQ}$ & $0.20 \pm 0.01$ \\
C20:0 & 2327 & $0.43 \pm 0.00$ & $<\mathrm{LOQ}$ & $0.57 \pm 0.00$ \\
C20:1(n-9) & 2356 & $0.14 \pm 0.00$ & $0.36 \pm 0.01$ & $<\mathrm{LOQ}$ \\
C24:0 & 2400 & $0.45 \pm 0.00$ & $<\mathrm{LOQ}$ & $<\mathrm{LOQ}$ \\
Saturated & & $53.11 \pm 0.01$ & $15.80 \pm 0.01$ & $61.15 \pm 0.05$ \\
Unsaturated & & $46.78 \pm 0.01$ & $84.19 \pm 0.03$ & $38.69 \pm 0.05$ \\
\hline
\end{tabular}

*KI: Kovats Index.

*LOQ: Limit of quantitation.

Tocopherols are naturally occurred in most vegetable oils. There are four types of tocopherols, including $\alpha$-, $\beta$-, $\gamma$-and $\delta$-tocopherols, with $\alpha$-tocopherol being the most abundant in foods and considered to have the highest nutritional value. On the other hand, studies revealed that various tocochromanols exhibit diverse health-promoting properties. Tocopherols are natural antioxidants, and the antioxidant and anti-inflammatory activities are more significant with higher $\gamma$-tocopherol contents [33,34]. The compositions of tocopherols of three seed oils are listed in Table 2. The seeds with high 
contents of tocochromanols were regarded as rich sources for tocopherols and tocotrienols for the stabilization of fats and oils against oxidative deterioration and for extensive application in dietary, pharmaceutical or biomedical products. The main ingredients were $\gamma$-T- $(31.88 \mathrm{mg} / \mathrm{kg})$ and $\delta$-T3tocopherols $(110.70 \mathrm{mg} / \mathrm{kg})$ presented in the seeds of $G$. hanburyi; $\gamma$-T3- $(42.59 \mathrm{mg} / \mathrm{kg})$ and $\gamma$-Ttocopherols $(35.19 \mathrm{mg} / \mathrm{kg})$ in $G$. multiflora; and $\alpha-(80.86 \mathrm{mg} / \mathrm{kg})$ and $\delta$-T3-tocopherols $(45.72 \mathrm{mg} / \mathrm{kg})$ in $G$. gaudichaudii, respectively.

Table 2. Tocopherol content (mg/kg) of three Garcinia seed oils

\begin{tabular}{lccc}
\hline \multirow{2}{*}{ Compound } & \multicolumn{3}{c}{ Content $(\mathbf{m g} / \mathbf{k g})$} \\
\cline { 2 - 4 } & $\boldsymbol{G}$. hanburyi & G. multiflora & G. gaudichaudii \\
\hline$\alpha-\mathrm{T}$ & $<\mathrm{LOQ}$ & $20.12 \pm 0.05$ & $80.86 \pm 0.03$ \\
$\alpha-\mathrm{T} 3$ & $3.82 \pm 0.03$ & $1.31 \pm 0.01$ & $2.12 \pm 0.04$ \\
$\beta$-T & $<\mathrm{LOQ}$ & $0.43 \pm 0.04$ & $1.54 \pm 0.02$ \\
$\gamma$-T & $0.45 \pm 0.01$ & $35.19 \pm 0.04$ & $6.30 \pm 0.02$ \\
$\beta$-T3 & $<\mathrm{LOQ}$ & $<\mathrm{LOQ}$ & $1.68 \pm 0.03$ \\
$\mathrm{P} 8$ & $<\mathrm{LOQ}$ & $7.15 \pm 0.04$ & $<\mathrm{LOQ}$ \\
$\gamma$-T3 & $21.68 \pm 0.02$ & $42.59 \pm 0.01$ & $1.86 \pm 0.05$ \\
$\delta$-T & $1.08 \pm 0.04$ & $3.60 \pm 0.03$ & $2.19 \pm 0.03$ \\
$\delta$-T3 & $110.70 \pm 0.03$ & $<\mathrm{LOQ}$ & $45.72 \pm 0.01$ \\
Total & $137.73 \pm 0.02$ & $110.37 \pm 0.02$ & $142.27 \pm 0.02$ \\
\hline
\end{tabular}

*LOQ: Limit of quantitation.

Table 3. Sterol composition ( $\mathrm{mg} / \mathrm{kg})$ of three Garcinia seed oils

\begin{tabular}{lccc}
\hline \multirow{2}{*}{ Compound } & \multicolumn{3}{c}{ Content $(\mathbf{m g} / \mathbf{k g})$} \\
\cline { 2 - 4 } & G. hanburyi & G. multiflora & G. gaudichaudii \\
\hline Cholesterol & $8.51 \pm 0.02$ & $9.33 \pm 0.01$ & $13.18 \pm 0.02$ \\
Brassicasterol & $144.42 \pm 0.03$ & $10.13 \pm 0.05$ & $<$ LOQ \\
24-Methylencholesterol & $6.78 \pm 0.02$ & $8.29 \pm 0.04$ & $<$ LOQ \\
Campesterol & $355.55 \pm 0.02$ & $197.41 \pm 0.02$ & $124.96 \pm 0.03$ \\
Campestanol & $594.45 \pm 0.04$ & $17.46 \pm 0.05$ & $<$ LOQ \\
Stigmasterol & $1871.53 \pm 0.03$ & $379.90 \pm 0.04$ & $118.15 \pm 0.01$ \\
$\Delta^{7}$-Camersterol & $140.59 \pm 0.02$ & $4.55 \pm 0.01$ & $<$ LOQ \\
$\Delta^{5,23}$-Stigmastadienol & $24.25 \pm 0.01$ & $7.18 \pm 0.02$ & $<$ LOQ \\
Chlerosterol & $89.31 \pm 0.05$ & $1.92 \pm 0.03$ & $<$ LOQ \\
$\beta$-Sitosterol & $339.57 \pm 0.03$ & $459.38 \pm 0.05$ & $312.56 \pm 0.01$ \\
Sitostanol & $21.67 \pm 0.02$ & $27.68 \pm 0.04$ & $<$ LOQ \\
$\Delta^{5}$-Avenasterol & $84.19 \pm 0.01$ & $44.91 \pm 0.03$ & $<$ LOQ \\
$\Delta^{5,24}$-Stigmastadienol & $86.76 \pm 0.03$ & $2.82 \pm 0.04$ & $<$ LOQ \\
$\Delta^{7}$-Stigmastenol & $149.27 \pm 0.04$ & $4.23 \pm 0.02$ & $<$ LOQ \\
$\Delta^{7}$-Avenastenol & $81.45 \pm 0.02$ & $1.04 \pm 0.03$ & $<$ LOQ \\
Total & $3998.33 \pm 0.02$ & $1176.25 \pm 0.03$ & $568.86 \pm 0.02$ \\
\hline
\end{tabular}

* Cholestanol is used as Internal standard (ISTD)

Sterols are important constituents of oils corresponding to the oil quality and are widely used to check the authenticity of oils [35]. Phytosterols are usually of interest due to their antioxidant activity and impact on health. This fraction has been considered as the major unsaponifiable fraction in many 
oils. The sterol composition in the Garcinia seed oils are presented in Table 3. From the data, three seeds contain the typical phytosterol compounds identified as campesterol, stigmasterol and sitosterol. Campestanol only occurred in the seeds of G. hanburyi $(594.45 \mathrm{mg} / \mathrm{kg})$. The most abundant sterol in the seeds of G. hanburyi was stigmasterol $(1871.50 \mathrm{mg} / \mathrm{kg})$ followed by campesterol $(355.55 \mathrm{mg} / \mathrm{kg})$ and $\beta$-sitosterol (339.57 mg/kg). Comparatively, the predominant sterols were $\beta$-sitosterol $(459.38$ $\mathrm{mg} / \mathrm{kg})$ and campesterol $(197.41 \mathrm{mg} / \mathrm{kg})$ in the seeds of G. multiflora; and $\beta$-sitosterol $(312.56 \mathrm{mg} / \mathrm{kg})$, campesterol $(124.96 \mathrm{mg} / \mathrm{kg})$, and stigmasterol $(118.15 \mathrm{mg} / \mathrm{kg})$ in the seeds of G. gaudichaudii. sitosterol is reported to have anti-hypercholesterolemic, anti-inflammatory, antibacterial, antifungal, and anti-hyperlipoproteinemic activities, as well as inhibiting carcinogenesis [36], and decreasing glycated hemoglobin and serum glucose levels, while increasing serum insulin levels [37]. Stigmasterol is used as a precursor in the manufacturing of semi-synthetic progesterone, a valuable human hormone that plays an important physiological role in the regulatory and tissue rebuilding mechanisms related to estrogen effects, as well as acting as an intermediate in the biosynthesis of androgens, estrogens, and corticoids. It is also used as the precursor of vitamin $\mathrm{D}_{3}$. The Upjohn company used stigmasterol as the starting raw material for the synthesis of cortisone [38]. Briefly, the high sterol contents of these three Garcinia seed oils may extend their application in the future.

Table 4. DPPH radical scavenging percentage (\%) of three Garcinia seed oils

\begin{tabular}{ccccc}
\hline $\begin{array}{c}\text { Concentration } \\
(\boldsymbol{\mu g} / \mathbf{m L})\end{array}$ & G. hanburyi & G. multiflora & G. gaudichaudii & $\begin{array}{c}\text { ascorbic acid } \\
\text { (Control) }\end{array}$ \\
\hline 100 & 85.20 & 81.37 & 84.54 & 86.11 \\
50 & 83.62 & 79.07 & 71.36 & 78.84 \\
25 & 81.55 & 71.61 & 46.92 & 39.15 \\
12.5 & 78.49 & 38.41 & 31.78 & 19.31 \\
6.25 & 44.16 & - & - & 9.42 \\
$\mathrm{IC}_{50}(\mu \mathrm{g} / \mathrm{mL})$ & $6.34 \pm 0.43$ & $14.27 \pm 0.30$ & $26.23 \pm 1.64$ & $6.63 \pm 0.57$ \\
\hline
\end{tabular}

Table 5. The ferric reducing ability of plasma FRAP $(\mu \mathrm{M} / \mathrm{g})$ of three Garcinia seed oils

\begin{tabular}{ccccc}
\hline $\begin{array}{c}\text { Concentration } \\
(\boldsymbol{\mu g} / \mathbf{m L})\end{array}$ & G. gaudichaudii & G. hanburyi & G. multiflora & $\begin{array}{c}\text { ascorbic acid } \\
\text { (Control) }\end{array}$ \\
\hline 2000 & 1475.37 & 2803.97 & 2701.40 & - \\
1000 & 873.79 & 2563.37 & 1640.17 & - \\
500 & 468.31 & 1727.18 & 931.26 & 3053.17 \\
250 & - & - & - & 2391.51 \\
125 & - & - & - & 1248.66 \\
\hline
\end{tabular}

Table 6. The Trolox equivalent antioxidant capacity TEAC (\%) of three Garcinia seed oils

\begin{tabular}{ccccc}
\hline $\begin{array}{c}\text { Concentration } \\
(\boldsymbol{\mu g} / \mathbf{m L})\end{array}$ & G. gaudichaudii & G. hanburyi & G. multiflora & $\begin{array}{c}\text { Trolox } \\
\text { (Control) }\end{array}$ \\
\hline 100 & 85.40 & 88.13 & 88.29 & - \\
50 & 54.90 & 84.85 & 82.35 & 91.73 \\
25 & 35.65 & 79.14 & 51.34 & 90.02 \\
12.5 & 21.93 & 57.58 & 22.99 & 89.44 \\
6.25 & 7.31 & 24.60 & 10.70 & 47.77 \\
3.125 & - & - & - & 17.48 \\
$\mathrm{EC}_{50}(\mu \mathrm{g} / \mathrm{mL})$ & $41.44 \pm 1.57$ & $11.71 \pm 0.22$ & $24.70 \pm 2.26$ & $6.68 \pm 0.83$ \\
\hline
\end{tabular}

DPPH radical scavenging activity and two other methods FRAP and TEAC were used to evaluate the antioxidant potentials of three extracted oils and the results demonstrated that all samples show moderate antioxidant potentials (Table 4, 5 and 6). At high concentration, all three-tested species do not show significant difference in the scavenging percentages with approximately $85 \%$ at $100 \mu \mathrm{g} / \mathrm{mL}$ and $80 \%$ at $50 \mu \mathrm{g} / \mathrm{mL}$, except G. gaudichaudii (71.36\%) according to DPPH assay and the results were the same for TEAC method with $87 \%$ at $100 \mu \mathrm{g} / \mathrm{mL}$ and $83 \%$ at $50 \mu \mathrm{g} / \mathrm{mL}$ and only $G$. gaudichaudii showed lower antioxidant capacity (54.90\%). At the tested concentration of $25 \mu \mathrm{g} / \mathrm{mL}$, 
two species $G$. hanburyi and G. multiflora remained the high percentages of scavenging, while $G$. gaudichaudii and ascorbic acid decreased rapidly, however, in FRAP and TEAC assays at lower concentration showed that G. gaudichaudii and G. multiflora antioxidant activity weaken rapidly in compared to G. hanburyi and the control. At the concentration of $12.5 \mu \mathrm{g} / \mathrm{mL}$ (DPPH and TEAC) or $500 \mu \mathrm{g} / \mathrm{mL}$ (FRAP) only G. hanburyi still exhibited high scavenging percentage (78.49\% and 57.58 $\%$ ) and $1727.18 \mu \mathrm{M} / \mathrm{g}$ respectively. In summary, in all three tested methods, the species G. hanburyi showed the strongest antioxidant activity $\left(\mathrm{IC}_{50}=6.43 \mu \mathrm{g} / \mathrm{mL}, \mathrm{EC}_{50}=11.71 \pm 0.22 \mu \mathrm{g} / \mathrm{mL}\right.$ ) which is quite similar to the value of ascorbic acid $\left(\mathrm{IC}_{50}=6.63 \mu \mathrm{g} / \mathrm{mL}\right)$ and Trolox $\left(\mathrm{EC}_{50}=6.68 \pm 0.83 \mu \mathrm{g} / \mathrm{mL}\right)$ . The two other species G. multiflora and G. gaudichaudii are slightly less active. The antioxidant activity could be due to the presence of $\alpha$-tocopherol (20.12 and $80.86 \mathrm{mg} / \mathrm{kg}$ ) in G. multiflora and $G$. gaudichaudii and also other phenolic compounds and unsaturated fatty acids.

\section{Conclusion}

In this work, the fatty acid, tocopherol, and sterol compositions from three Garcinia seeds were studied for the first time. The Garcinia seeds contained a high amount of oil (11.71-29.91\%). The major monounsaturated and saturated fatty acids were oleic acid $(82.97 \%$ in G. multiflora, $45.37 \%$ in G. hanburyi) and stearic acid (58.87\% in G. gaudichaudii and $50.12 \%$ in G. hanburyi). Although the three studied seeds were belong to the same genus, the contents of fatty acids were significantly different among the samples, especially in G. multiflora. The seed oil of this species contained mainly oleic acid up to more than $80 \%$, but $45.50 \%$ in G. hanburyi and $7.82 \%$ in G. gaudichaudi comparatively. Linoleic acid was presented in the seed oil of G. gaudichaudi (30.46\%), however, its concentration in the two other species was lower than $1 \%$. Both two species G. gaudichaudi and $G$. hanburyi contained stearic acid C18:0 at high concentrations (more than 50\%). These two species were only different in the contents of linoleic acid $(30.46 \%$ in G. gaudichaudi and $0.77 \%$ in $G$. hanburyi, respectively). Steroids were predominant in these oils, including several typical sterols such as campesterol, stigmasterol and sitosterol. The most abundant sterol in the seeds of G. hanburyi was stigmasterol $(1871.53 \mathrm{mg} / \mathrm{kg})$, whereas it was $\beta$-sitosterol in the seeds of $G$. multiflora $(459.38 \mathrm{mg} / \mathrm{kg})$ and G. gaudichaudii $(312.568 \mathrm{mg} / \mathrm{kg})$. The seed oils from three Garcinia species showed moderate antioxidant activity evaluated using three antioxidant assays DPPH, FRAP and TEAC and G. hanburyi displayed the strongest activity with $\mathrm{IC}_{50}$ value of $6.34 \pm 0.43 \mu \mathrm{g} / \mathrm{mL}$ or $\mathrm{EC}_{50}=11.71 \pm 0.22 \mu \mathrm{g} / \mathrm{mL}$.

\section{Acknowledgments}

The authors are thankful to the Ministry of Science and Technology, Vietnam (44/2014/HĐ$\mathrm{NĐT)} \mathrm{for} \mathrm{the} \mathrm{financial} \mathrm{support} \mathrm{of} \mathrm{this} \mathrm{research.}$

\section{ORCID}

Doan Lan Phương: 0000-0003-2514-9824

Nguyen Thi Thuy: 0000-0002-1590-7305

Pham Quoc Long: 0000-0001-6964-2341

Pham Minh Quan: 0000-0001-6922-1627

Tran Thi Thu Thuy: 0000-0001-8591-9152

Pham Thi Hong Minh: 0000-0003-0733-0726

Ping-Chung Kuo: 0000-0003-3019-1138

Tran Dinh Thang: 0000-0003-1129-8941

\section{References}

[1] L.P. Wong and P.J. Klemmer (2008). Severe lactic acidosis associated with juice of the mangosteen fruit Garcinia mangostana, Am. J. Kidney Dis. 51, 829-833.

[2] V.V. Chi (2003). Dictionary of Vietnamese medicinal plants, Vol 1. Medical Publishing House, Hanoi.

[3] V.V. Chi (2012). Dictionary of Vietnamese medicinal plants, Vol 2. Medical Publishing House, Hanoi.

[4] D.T. Loi (1995). Medicinal plants and medicines in Vietnam. Science and Technology Publishing House, Hanoi. 
[5] L.D. Moi (2007). Compounds with biological activity in the genus Garcinia. Scientific Report on Ecology and Biological Resources, Second National Scientific Conference, Agricultural Publishing House, Hanoi.

[6] L.N. Han and T.T. Bach (2015). Economic importance of the family Clusiaceae in Vietnam, In: Proceedings of the National Science Conference Ecology and Biological Resources $6^{\text {th }}$.

[7] A. Panthong, P. Norkaew, D. Kanjanapothi, T. Taesotikul, N. Anantachoke and V. Reutrakul (2007). Anti-inflammatory, analgesic and antipyretic activities of the extract of gamboge from Garcinia hanburyi, J. Ethnopharmacol. 111, 335-340.

[8] Y. Sukpondma, V. Rukachaisirikul and S. Phongpaichit (2005). Antibacterial caged-tetraprenylated xanthones from the stem bark of Garcinia scortechinii, Planta Med. 71, 165-170.

[9] Y.M. Lin, H. Anderson, M.T. Flavin, Y.H. Pai, E. Mata-Greenwood, T. Pengsuparp, J.M. Pezzuto, R.F. Schinazi, S.H. Hughes and F.C. Shen (1997). In vitro anti-HIV activity of bioflavonoids isolated from Rhus succedanea and Garcinia multiflora, J. Nat. Prod. 60, 884-888.

[10] J.H. Wu, Y.T. Tung, C.F. Chyu, S.C. Chien, S.Y. Wang, S.T. Chang and Y.H. Kuo (2008). Antioxidant activity and constituents of extracts from the root of Garcinia multiflora, J. Wood Sci. 54, 383-389.

[11] K. Aitzetmuller and K. Vosmann (1998). Cyclopropenoic fatty acids in gymnosperms: The seed oil of Welwitschia, J. Am. Oil Chem. Soc. 75, 1761-1765.

[12] A.B. Imbs and L.Q. Pham (1995). Lipid composition of ten edible seed species from North Vietnam, $J$. Am. Oil Chem. Soc. 72, 957-961.

[13] International Organization for Standardization (1988). Oil seeds - Determination of oil content, ISO Geneva, Switzerland, Standard No. 659.

[14] International Organization for Standardization (1988). Animal and vegetable fats and oils-preparation of methyl esters of fatty acids, ISO, Geneva, Switzerland, Standard No. 5509.

[15] International Organization for Standardization (2006). Animal and vegetable fats and oilsDetermination of tocopherol and tocotrienol contents by high-performance liquid chromatography, ISO, Geneva, Switzerland, Standard No. 9936.

[16] International Olive Council (2001), Determination of the composition and content of sterols by capillary-column gas chromatography. Spain; Madrid, COI/T, 20/Doc. No. 10 Rev.

[17] International Olive Council (2013), Determination of the composition and content of sterols and triterpene dialcohols by capillary column gas chromatography. Spain; Madrid, COI/T, 20/Doc. No. 30/Rev.

[18] N. Saeed, M.R. Khan and M. Shabbir (2012). Antioxidant activity, total phenolic and total flavonoid contents of whole plant extracts Torilis leptophylla L., BMC complementary Altern. Med. 12, 221.

[19] E.S. Adithya, M.S. Lakshmi, P.H. Christabel and J.M. Sasikumar (2013). In vitro antioxidant, anti-lipid peroxidation activities and HPLC analysis of methanol extracts from bark and stem of Mahonia leschenaultia takeda, Asian J. Plant Sci. Res. 3, 116-126.

[20] P. Yuvaraj, A. Subramoniam, T. Louis, V. Madhavachandran and M.L. Narasu (2013). Attenuation of expression of cytokines, oxidative stress and inflammation by hepatoprotective phenolic acids from Thespesia populnea Soland ex Correa stem bark, Ann. Phytomed. 2, 47-56.

[21] H.A.M. Van Der Vossen and B.E. Umali (2001). Plant resources of South-East Asia, Vol 14, Vegetable oils and fats. Backhuys Publishing House, Leiden, Netherlands.

[22] M.M. Patil, A.M. Muhammed and K.A. Anu-Appaiah (2016), Lipids and fatty acid profiling of major Indian Garcinia fruit: A comparative study and its nutritional impact, J. Am. Oil Chem. Soc. 93, 823836.

[23] B. Matthaus, K. Vosmanna, L.Q. Pham and K. Aitzetmüllera (2003). FA and tocopherol composition of Vietnamese oilseeds, J. Am. Oil Chem. Soc. 80, 1013-1020.

[24] D.J. Murphy (1996). Engineering oil production in rapeseed and other oil crops, Trends Biotechnol. 14, 206-213.

[25] E.A. Bailey (1951). Industrial oil and fat products. International Publishers, New York.

[26] I.A. Al-Saleh, G.Billedo and I.I. El-Doush (2006). Levels of selenium, DL- $\alpha$-tocopherol, DL- $\gamma$ tocopherol, all-trans-retinol, thymoquinone and thymol in different brands of Nigella sativa seeds, $J$. Food Compos. Anal. 19, 167-175.

[27] M.M. Patil, A.M. Muhammed and K.A. Anu-Appaiah (2016). Lipids and fatty acid profiling of major Indian Garcinia Fruit: A comparative study and its nutritional impact, J. Am. Oil Chem. Soc. 93, 823836.

[28] I.A. Ajayi, R.A. Oderinde, B.O. Ogunkoya, A. Egunyomi and V.O. Taiwo (2007). Chemical analysis and preliminary toxicological evaluation of Garcinia mangostana seeds and seed oil, Food Chem. 101, 999-1004.

[29] S.M. Grundy (1989). Monounsaturated fatty acids and cholesterol metabolism: implication for dietary recommendations, J. Nutr. 119, 529-533. 
[30] C.K. Chow (2008). Fatty acids in foods and their health implications. CRC Press, Boca Raton.

[31] J. Beare-Rogers, A. Dieffenbacher and J.V. Holm (2001). Lexicon of lipid nutrition, Pure Appl. Chem. 73, 685-744

[32] N. Turner and T.W. Mitchell (2011). The $\omega-3$ and $\omega-6$ fats in meals: A proposal for a simple new label, Nutrition 27, 719-726.

[33] K. Saldeena and T. Saldeen (2005). Importance of tocopherols beyond alpha-tocopherol: evidence from animal and human studies, Nutr. Res. 25, 877-889.

[34] G.S. Anna, E. Sikorska, I. Khmelinskii and M. Sikorski (2007). Tocopherol content in edible plant oils, Pol. J. Food Nutr. Sci. 574, 157-161.

[35] M.D. Salvador, F. Aranda, S. Gomez-Alonso and G. Fregapane (2001). Cornicabra virgin olive oil: A study of five crop seasons. Composition, quality and oxidative stability, Food Chem. 74, 267-274.

[36] R. Gupta, A.K. Sharma, M.P. Dobhal, M.C. Sharma and R.S. Gupta (2011). Antidiabetic and antioxidant potential of $\beta$-sitosterol in streptozotocin-induced experimental hyperglycemia, J. Diabetes 3, 29-37.

[37] R. Raicht, B. Cohen and E. Fazzini (1980). Protective effect of plant sterols against chemically induced colon tumours in rats, Cancer Res. 40, 403-405.

[38] K. Yasukawa, M. Takido, T. Matsumoto, M. Takeuchi and S. Nakagawa (1991). Sterol and triterpene derivatives from plants inhibit the effects of tumour promoter and sitosterol and betulinic acid inhibit tumour formation in mouse skin two stage carcinogenesis, Oncology 41, 72-76.

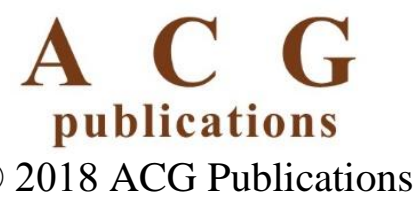

